\title{
English as an International Language: A critical approach
}

\author{
Luciana Casotti Moulin ${ }^{1}$, Carlos Roberto Pires Campos ${ }^{2}$ \\ ${ }^{1}$ (Yazigi English School, Vila Velha Branch, Brazil) \\ ${ }^{2}$ (Humanities Graduate Program, Instituto Federal do Espírito Santo, Vitória, Brazil)
}

\begin{abstract}
The aim of this work is to study the pathway in which the English language has been through, to analyze the predictions concerning to he future of the language, the number of speakers, its consequences for other languages, including aspects of cultural imperialism and to observe how these impacts will reflect on the teaching of the language itself. These objectives were pursued through the reading of theoretical conceptions, after done that it is proper to assume that the English language will, in some years, become an International Language with more second languages speakers than the native ones, and up to now there is no other language that may rival English in it's role of "Lingua Franca".
\end{abstract}

Keywords: cultural imperialism, international language

\section{Introduction}

The research aims at discussing the use of English as an International Language with emphasis on the social and cultural aspects. For this, three chapters are presented, the first one discusses the decline of the native speakers and the position of English in the $20^{\text {th }}$ century, the second talks about the trends related to the future of the English language and the last one debates the impacts already caused both in the English language and its teaching aspects. This study used theoretic qualitative approach. After established the main theme, essays, articles and books were selected for scanning and skimming readings, summaries were build and after they were confronted in order to construct a significative text, with consistence. An analytic approach was employed for the final writing. Data analysis produced the research results. The main intention was to put into evidence the pathway of the English language in order to become a "Lingua Franca" and its consequences in the educational field.

\section{II. less English Native Speakers?}

Graddol (1997) discusses about the place of English in the world linking it to the growing number of people who speak and who need English nowadays. He says this phenomenon started in the $19^{\text {th }}$ century, with the Neocolonialism. During the first part of the $19^{\text {th }}$ century, French was the language of diplomacy, only in its second half, English challenged the status of French as an international language. The combination of both the industrial development and the expansion of the British Empire was the main factor for a general adoption of English as an international language. French was considered, at that time, both a catholic language and a language of ideas and diplomacy, while English was the protestant working language of commerce.

The essay intends to examine the trends in the English language usage and provides the basis for forecasting the number of people speaking English in the world. About this, Graddol (1997) establishes important criterion for projecting future trends in the growing number of native speakers of English. This criterion is based upon two kinds of data: the forecasting for populations of countries in which English is spoken as a first language and the estimative of the proportion of those populations for whom English is a mother tongue. MaC Arthur (1998) lists 113 territories that use English on sustained basis, but then we come to one of the most problematical issues in linguistic: What counts as a native speakers? Even in monolingual countries as the U.S. and England a significant proportion of the population speaks other languages than English as their first language. For Graddol (1997), there are 337 million of people who use English as first language speakers (L1), but the growth of L1 speakers will slow down in about twenty years, leading to a likely total population of around 433 million in 2050.

The apparent decline in the number of natives of English, however, does not reflect the decline in importance of English language nowadays. The future of English will be determined less by the number and economic power of its native speakers and more by the number of people who use the language as a second language (L2). Projections based only in expected population changes suggest that the number of people who use English as a L2 will grow from 235 million to 462 million during the next fifty years, what indicates that there will be a crucial change in the balance between L1 and L2 and L2 speakers may overtake L1 speakers. However, if we include African countries, Asians countries and Latin America ones, where the statistics are not very much reliable, we reach to a number of 354 million of L2 speakers and in 2050, 668 million. (MC ARTHUR, 1998). 
Outside of the UK and the Irish Republic, English is considered a foreign language in Europe, but this view may be out of date because Europe is rapidly integrating itself as a multilingual area in which English play an important role as a second language. Researchers concluded that nearly one third of citizens of the non English-speaking countries in Europe can speak English well enough to keep a conversation, in other words, English is becoming a L2 in Europe.

The language shift towards English in Europe, that reflects an increase in bilinguism and multilinguism, rather than abandonment of other languages, undoubtedly has many causes, including significant changes to language curricula in school; exchange programmers encouraging young people to move between EU members; the growing importance and utility of English as L2; the greater exposure to English as cultural product. Some countries accept these changes faster, for instance, Spain, and other take longer time, as Portugal. Projections show that one third of the EU population who speak English will grow roughly two thirds for 2050.

During the $20^{\text {th }}$ century, the reconstruction of a New Europe has resulted in new formations of identity; greater mobility; and a new hierarchy of languages, which places most Europeans citizens in a plurilingual context.

Lately, there have been two approaches to defining second language users, both focusing on the status of English in the speakers' speech community. The first identifies 'L2 countries', where English serves as a role in intranational communication. The second approach defines an L2 speech community as one which is "norm creating' that is, developing its own institutionalized variety of English. These are the so-called 'New englishers', mainly in former British colonial territories.

The decline of the native speaker in numerical terms is likely to be associated with changing ideas about the centrality of the native speaker concerns to the norms of usage. The native speaker is claimed to have access to a much higher source of data than a researcher could ever discover by studying a speaker's actual utterances.

Beyond all this discussion, it is possible to point out some questions, like as: which English will be used as standard, British or American? Will the great number of learners keep looking for a native proficiency? This discussion can lead us to what has being called Englishzation. Researches show that the English language is in a process of globalization and for better understand it, it's necessary to analyze it, not only linguistically, but also economically, politically and historically. The fact is that a language englobes all aspect of daily life, so, we all need to worry about the cultural dimensions and diversity of this language.

The dominance of the English language is based upon a process of linguistic "hierarchization", in which, the dominant is favored in the place of the dominated, therefore it is the responsibility of the researchers of the language to investigate the relationship between the use of the language and the contemporary power structures. If linguistics can't situate the study of global language in an intellectual and material position, then discourses may remain as intellectual escapism. Nowadays, the English language joins North and South concerning the finance, technology and entertainment fields and besides the fact that the global flows from North to South and from South to North, the predominant languages in this relationship are the ones from the North region with special prominence to English. For the authors cited until now, the Englishsation and the study of the language can't be related as neutral activities because even the ones who claim to be analyzing the languages policy above politics, many times end up confusing neutrality with a myopia in the social, political and humanitarian field.

For Crystal (1997) the users of the English language besides being influenced by the whole process of globalization are involved in power structures that legitimize the process to validate a language and, as an example of this legitimation, there is the influence of the US on Europe, basically, after the Marshall Plan, right after The Second World War. The injection of the US capital indeed had the effect to integrate European economics into patterns determined by US global economics interests. In theory, the architects of the new Europe proclaimed that culture and linguistic diversity was to be maintained but the reality is quite different (because of the facts above listed) with the English language in evidence rather than French and German.

In most authors' opinion, there are many questions, without answer: is Europe moving towards diglossia, with English as a second language for elites other than the Brits and the Irish? Can a more substantial degree of multi-directional and reciprocal multilinguism be established? Is there any informed discussion of the viability of alternatives for this? The points need to be studied in specific local linguistic ecologies as well as at a macro level.

For Mazzuri (1997), multilinguism is entrenched in Danish higher education, although, by no means, it can threaten Danish, but still some questions need further analyses as: will English be emphasized with or without the mother tongue? Will there be any impact on local music or movie? What will be the significance for politicians who use English with moderate proficiency when talking to the world press? Will it be possible to specify the reason for the use English in certain context, and its consequence for other languages? These questions aren't concentrated in Denmark, many studies about these aspects (Englishsation) are appearing in East Africa (MAZZURI, 1997) and in Asia (BAUMGARDNER, 1966). 
There is evidence from several countries of domains, genres and rhetorical traditions that are succumbing to the force of Anglo American dominance. Kachru (1997) suggest that there should be a paradigm shift in the study of the diffusion and impact of English, that it should be less ethnocentric and more concerned to the linguistic and cultural pluralism. For Medgyes (1994), the native speaker authority is now under an impressive non-native speaker challenge, this makes us think that English is a potential of infinitive variability rather than an instrument of power due to its roots on different parts of the world.

To finish this part of the discussion, the authors defend that what they criticize is the way with which English is legitimated in different contexts. English linguistic imperialism serves particular interests of some local elites and some global transactions. For them, what counts is that, in principle, all languages can be used for all purposes and that the use of English should not be based on differential and hierarching access to the language. Only equal access to the English language will make Englishzation serves to democratic principles and then may cease functioning as a Tyrannosaurus Rex, particularly in scientific areas (SWALES, 1997).

Our task now is to debate about the English language facing its globalization as a "Lingua Franca", with emphasis is in some aspects about its teaching to non-native and also its future in post-modern times. Some of these questions demand a high attention: How and why English became an international language? How is the relation of the different speakers of English, native x nonnative?

Graddol (1997) says that there were two preconditions for the establishing of English as a global language; first the British empire with its communities of English speakers settled around the world and the ride of the US in the $20^{\text {th }}$ century as a world superpower. Second for the spread of English, the aftermath of World War II was decisive. According to Eco (1995) had Hitler won World War II and we should probably today use German as a global language. Crystal (1997) estimates that after the end of WW II, several international agencies were established to help reconstruction and $85 \%$ of these international organizations used English as one of their working language. She also estimates that $99 \%$ of European organizations cite English as a working language, as opposed to $63 \%$ French and $40 \%$ German. Besides the international agencies, there were the financial institutions also created after WW II, that helped the spread of the English language.

As might be expected, some disciplines have been more affected by the English language than others. Physics is the most globalized and Anglophone, followed a close second by other pure sciences. It is not just in scientific publishing but in book publications a whole that English rules supreme. Worldwide English is the most popular language in publications.

The position of English in the world today is thus a join outcome of Britain's colonial expansion and the more recent activity of the US. Any substantial shift in the role of the US in the world is likely to have an impact on the use and attractiveness of the English language amongst those for whom it is not a first language. Crystal (1997) says there are a little over 377 millions speakers of English as a L1 but the aggregated population of all countries in which English has any special status represents one third of the world1s population. These data seem to show that many people have used English for professional purposes but do they speak it?

There are three types of English speakers in the world today, each one with a different relationship with the language. First language (L1) speakers are those for whom English is a first-and often only- language. These native speakers live in countries in which the dominant culture is based on English. These countries, however, are experiencing increasing linguistic diversity as a result of immigration. Second language speakers (L2) have English as a second or additional language. Speakers here might use o local form of English, but many also can be fluent in international varieties. The third group of English speakers are the growing number of people learning English as a Foreign Language (EFL).

The first two kinds of English-speaking community result from three different colonial processes; in the first type, exemplified by America and Australia, substantial settlement by first language speakers of English displayed the pre-colonial population. In the second, typified by Nigeria, sparser colonial settlements maintained the pre-colonial in subjection and allowed a proportion of them the access to learning English, as a second, or additional language. There is yet a third type, exemplified by the Caribbean Islands of Barbados and Jamaica. Here, a pre-colonial population was replaced by a new laborers from elsewhere, principally west Africa. The long term effect of the slave trade on the development of the English language was immense.

Each colonial process had different linguistic consequences. The first type created a diaspora of native speakers of English (US, Canada, South Africa, Australia, New Zealand), with each settlement eventually establishing its own national variety of English. The second (India, West Africa, East Africa) made English as an elite second language, frequently required for further education and government jobs. The linguistic consequences of the third type were complex, including the creation of new hybrid varieties of English called Creoles.

Dividing English speakers into three groups is a time-honoured approach to language use and, though not without its problem, is a useful starting point for understanding the patterns of English worldwide. These three groups have become known (after KACHRU, 1985) as the "inner circle", the "outer circle" and the "expanding circle. One of the drawbacks of this terminology is the way it locates the native speaker and native 
speaking countries at the center of the global use of English and, by implication, the sources of model of correctness, the best providers of teachers and English -language goods and services consumed by those in periphery.

Nowadays, we can find English spoken as a first language in over 30 territories and the areas in which English is used extensively as a second language usually develop a distinct variety of English which reflects other languages used alongside English. Parts of the world where such varieties (New Englishes) have emerged are the formal colonial territories in South Asia, South- East Asia, Africa and the Caribbean.

The number of people learning English has, in recent years, risen rapidly. The main distinction between a fluent EFL speaker and a L2 speaker depends on whether English is used within the speaker's community and thus form forms part of the speaker's cultural identity. In many parts of the world, there are ongoing shifts in the status of English. In some countries, the use of English for intranational communication is greatly increasing. These countries can be regarded as in the process of shifting towards L2 status. In existing L2 areas, a slight increase in the proportion of the population speaking English would significant increase the global total of second-language speakers. In many L2 areas, there is a trend for professional and middle classes who are bilingual in English to adopt English as the language of the home. English is thus acquiring new first-language speakers outside the traditional native-speaking countries.

\subsection{Language hierarchies}

For a full understanding of the role of English in a world where the majority of its speakers are not first-language speakers it is required an understanding of how English relates to the other language which are use alongside it. The European concept of bilingualism reflects an idea that each language has a natural geographical home and that a bilingual speaker is, therefore, someone who can converse with monolingual speakers from more than one country. The bilingual speaker is thus imagined to be someone who is like a monolingual in two languages at once. But many of the world's bilingual or multilingual speakers interact with other multilingual speaker and use each of their languages for different purposes. Languages in multilingual areas are often hierarchically ordered in status. To the extent that such relationships are institutionalized, the hierarchy can be thought of as applying to countries as much as to the repertoire of individual speakers.

Where English has a place alongside languages in a local language hierarchy, speakers will normally use their first language in different contexts from those in which they use English. Whereas the first language may be a sign of solidarity or intimacy, English, in many bilingual situations, carries nuances of social distance, formality or officialdom.

Experienced users of English as a foreign language may acquire communicative skills, which are different from those of native speaker, reflecting the more hazardous context of communication in which they are, routinely, finding themselves. However, the strategies employed by non-native speakers remain an under researched area of English usage, despite of the fact that these strategies could help a lot the process of learning a second language.

Until this point, we have discussed the hierarchy of the languages in the globe nowadays. The purpose that seems to be important to dissert from now on is to confirm how English will behave in the future and how its future will be.

\section{The Future Of The English Language}

The rise of English was foreseen in the $19^{\text {th }}$ century. Indeed, wild speculations began to circulate about the growth of the number of English speakers in the coming century, based upon projections of current trends. Bailey (1992 p.111) reviews some of these accounts: "In England it doubles in fifty years therefore in a century (in 1970) it will be 124,000,000. In the United States, in Canada, in Australia, it doubles in twenty-five; therefore it 736,000,000. Probable total of the English speaking race in 1970, 860,000,000. Projections say that English speakers for the year 2020 will exceed a billion. The reality is that there are only about 375 million native speakers of English. The $19^{\text {th }}$ century commentators imagined that the growth in the number of native speakers would follow a straight-line progression. But most social changes don't follow a linear pattern. Rather, a change begins slowly, gathers speed and then soon slows down.

Some changes have a natural end point, but this, in many cases, is less certain and dependent on a complex interaction of factors. For example, an increase in number of children learning English at school is limited ultimately by the size of the global school population. But, in practice, the limits are lower, many countries lack qualified teachers or other resources to make the teaching of English in primary schools effective. However if new method of languages teaching were developed, or if there were a shift in public-sector resources, then the end point would move and a new S-shaped trajectory would become established.

As Bailey (1992) suggests, there are two common reasons for mistaken forecasting: first, extrapolating in a linear fashion from trend data gathered during the period of most rapid change; second, failing to recognize an underlying trend because of local or temporary variation. A third common error arises when it is assumed 
that the trend, which is currently most visible, will remain the dominant factor in the future. Sometimes, trends change directions in a cyclical but predictable way. For example, many thousands of young people visit Britain each year to enroll on English languages courses, a demand that rises over summer. Seasonal cycles like this must be taken into account when assessing underlying trends. It may be that other factors with cyclical patterns also vary trend data- the regular upturns and the downturns in the economy of any country known as the "business cycle". During a recession, there will be fewer jobs in the touristic industry or less opportunities for the kind of casual job that language students often require to support themselves while taking courses.

Identifying trends is therefore of great help to planners and strategists, but generally they need to be interpreted with awareness and caution.

\subsection{English as a "Lingua Franca"}

There has no reason to believe that any other language will appear within the next 50 years to replace English as a global "Lingua Franca". The position of English has arisen from a particular history that no other language can, in the 21 th century, repeat. It is possible to say that no language will occupy the monopolistic position which English has achieved by the end of the $20^{\text {th }}$ century.

Yet, there are still some factors that may threaten the position of English in the world in the future. First, there is a growing competition from other languages outside Europe and it would not be surprising if Mandarin or Spanish would emerge as an important language for the region's school. Second, the educational system in any multilingual country must consider the several languages used within the country. Third, regionalization may encourage the use of a non-english "Lingua Franca" for trading purposes. Greater use of Spanish in South America, for example, may affect the popularity of English in Brazil, just as interest in learning English in Hong Kong has recently been affected by the perceived priority of mandarin. And fourth, a new political spirit may encourage the study of languages from adjacent countries, rather than those from a different cultural and economic region.

Another significant factor in determining the relative position of world languages in this century has been called language shift- where individuals and whole families change their linguistic allegiances. Although such shifts are relatively slow, they are surprising difficult to predict. In the next 50 years or so, we can expect substantial language shift to occur as the effects of economic development and globalization are felt in more countries.

It is clear that sheer numbers of native speakers do not, in themselves, explain the privileged position of some languages. Crystal (1999 p.7) suggests that a language becomes an international language for one chief reason: "the political power of its people - especially its military power." Historically, that might been true: in the future, it will be less clearly military power that provide the international backing for languages, because of changes in the nature of national power, in the way that cultural values are projected and in the way markets are opened for the circulation of goods and services. Some authors have focused on economic and demographic factors to explain this privilege.

Bayle (1992) draw on two forecasting models in his book to analyze the future of English. The first, which he refers as the "Hook model" was devised by the Australian economist Gus Hooke. The model provides long-term forecast of the global economy, including the education and training sector. It also provides projections of the demand for different languages in education through to the year 2050. The second forecasting model, the 'Engno model' has been constructed by the English Company (UK) Ltd to calculate the index of 'global influence' taking into account various economic factors. The model also includes demographic factors, such as the number of young speakers and rates of urbanization. Finally, it takes into account the human development index (HDI) for different countries. This model of global influence thus generate a new kind of league table among languages, which weights languages not only by the number and wealth of their speakers, but also by the likelihood that these speakers will enter social networks which extend beyond their locality. No strong claims have been made for the validity of this index that seems to capture something of the relations between world language in which other models, based crudely on economic factors or numbers of native speakers, have failed. It shows that English is, on some criteria at least, a long way ahead of all other languages, including Chinese.

The advantage of the Engco index is the way it can be used to generate projections. Preliminary results indicate that, on this basis, Spanish is one of the languages which will rise most quickly. The nearest rivals to English - German, French and Japanese, will grow much more slowly. The relative position of the top six English, German, French, Japanese, Spanish and Chinese) are likely to change during the coming decades, but is unlikely that any other language will overtake English. The changing status of languages will create a new language hierarchy for the world.

Up to now, there is a growing concern about endangered languages but very little debate about the management of large languages, of which English is the largest. A more sensitive approach will be needed in the future, recognizing that English is not a universal "panacea" for social, economic and political ills and that 
teaching methods and materials, and educational policies, need to be adapted for local contexts. The world is becoming aware of the fact of endangered languages and more anxious over the long-term impact of English on world cultures, national institutions and local ways of life. Perhaps a combination of circumstances - such as shifting public values, changed economic priorities and regional political expediency - could bring about a serious reversal for ELT providers at some point in the future.

There are several lessons here for English and those who supply English language goods and services. Public attitudes towards massive language loss in the next few decades, for example, is unpredictable. It would be easy for concerns about this issue to become incorporated into the wider environmental consciousness that seems to be spreading around the world. The spread of English might come to be regarded in a similar way as exploitative logging in rainforests: it may be seen as providing a short-term economic gain for a few, but involving the destruction of the ecologies which lesser-used languages inhabit, together with consequent loss of global linguistic diversity.

\subsection{Demography}

The United Nation estimate that the global population in 2050 will be 11,54 billion. Population trends differ greatly from country to country, however, this in turn, means that as the demographic shape of the world changes, so will the relative status of different languages.

The languages people speak show two main influences: first, the speech community they are born, which for an increasing number of the world's population is a multilingual one; and second, the languages people learn through life as a consequence of education, employment, migration or increased social mobility. The languages that people use in their everyday interactions do not change rapidly, unless a speaker's social circumstances quickly change. Multilingual speakers may add languages during their lifetime and they may find that another becomes less used. But major language shift, from one first language to another, is usually slow, taking place across generations. Hence, if we take into account current patterns of language used amongst the young, including infants and teenagers, we can make a fair prediction about patterns of language use in 50 years time,

However, population growth is getting slow in European countries: roughly equal percentages of the population are under the age of 15 and over the age of 65 (The Economist, 1996). In European countries, the population is increasingly becoming younger. This global shift in the location of young people will have significant linguistic consequences. Since young people are key agents for language changes and development, while other people tend to be more stable in speech habits, we can expect patterns of language change to be marked in those countries of increasing youth: Africa, Asia and South America. This combination of factors will make Asia and Latin America potentially significant regions of language change in the next century.

In the $20^{\text {th }}$ century, patterns of immigration partially reversed as a consequence of decolonization, many families came to Britain from the Indian sub-continent and the Caribbean, while immigration policies of Australia encouraged migration from Asia rather than from Britain and Europe. As a consequence, highly multilingual cities have arisen in countries that imagined themselves to be predominantly monolingual English speaking.

The future for an increasing number of the world's population will be an urban one: the UNDP suggests the proportion of people living in towns and cities will be over $50 \%$ by 2050 (UNDP, 1966). Urbanization is likely to have wide-reaching effects on the world's language. This is the kind of environment where social and cultural practices are transformed and where languages varieties and speech habits emerge. Furthermore, new language varieties emerging from large, densely populated cities are usually economically and culturally significant.

Urbanization thus has important effects on language demography. New languages emerge, others change, some are lost. In the world's cities- the nexus for flows of people, goods and ideas-the spread of English will be the first felt and most keenly; new patterns of English use will arise amongst second-language speakers. The concept of globalization includes the idea both of flow and counter-flow, producing a tension between the global and the local. The English language flows into other languages, which adopt English words and phrases. English also "colonizes" the space the other languages by taking over certain communicative domains. But local languages also influences English, giving rise to new hybrid languages varieties in second-language-speaking areas. Appadurai (1990) identifies five global flows in terms of metaphorical landscape. These he terms ethnoescapes (people movement), techoescapes (technology transfer, technology convergence), financescapes (flow of capital and money), mediascapes (flows of audio-visual product but also the images and narratives they convey) and ideoscape (flows of ideas and ideologies).

The ultimate drivers of language are the people who use it. People move extensively: for business or education, as tourists and pilgrims, as a migrant workers and immigrants, as refugees and exiles, taking with them language and culture. Tourism is one well-documented form of people flow, which has a significant impact on the use of English. International travel has a globalizing effect. People are brought together, business 
and institutions form relationships and interdependency and closer communication. And, more directly than many other kinds of flow, international travel brings people from different background together, promoting the need to learn a language in common. We can assume that international traffic within a single region will encourage the use of a regional language. In many parts of the world, English is regarded as a language of power, success and prestige. English education is a sensitive matter In many countries, this is because of the distribution of English proficiency that may affect the 'balance of power' between ethnic groups and for that reason to be subject to political management.

One of the main linguistic issues facing the world in the $21^{\text {st }}$ is the extinction of a substantial proportion of the world's language.This tendency towards reduced linguistic diversity is the outcome of global demographic and economic trends: the local cultures and lifestyles that supported small community languages are disappearing and their speakers are usually those with least political and cultural power.

\section{Impacts On English}

It has generally been assumed that the ultimate goal of English language learners is to achieve nativelike competence. Yet, as more and more users of English come to use the language alongside one or more others, their use will significantly differ from that of monolingual speakers and because bilingual speakers of English have different needs in using the language than do monolingual speakers, any comparison is unwarranted.

Shidhar and Shidar (1994) provide critique of traditional SLA research assumptions in regard to bilingual users of English outside Inner Circle countries. They defend that much SLA theory is not relevant to an investigation of these speakers because it often rest on assumption that were developed and tested primarily in reference to the learning of English and European language in the USA, with little input from the learning of English in other countries. There are still some other assumptions that underline many of the traditional SLA researchers, one of them is that what the input learners have available is extensive and intensive enough for them to acquire nativelike competence but often the learner is not exposed to the full range of styles, structures, and speech acts that supposedly are necessary to acquire native like proficiency. The other is that in Outer and Expanding Circle countries, the role of the learner's first language is considered in terms of how it facilitates the acquisition of English rather than considering how English contributes to an overall communication pattern in a multilingual setting.

For much of the researchers, the ideal motivation for learning English is integrative, which might entail admiration for the native speakers of the target language and a desire to be a real member of such culture. However, in many countries, the acquisition of English is driven by what is typically called instrumental motivation, in what we can include the desire to pass an English examination, to read books in English, or to access information in the internet.

The authors argue that the lack of applicability of many assumptions underlying current SLA research is particularly disturbing the reason why English learners outside the Inner Circle constitute one of the most significant segments of second language acquires in the world today and to better study it, we have to put aside the prevalent assumption in much SLA research that the goal of English language is to achieve nativelike competence. It is important to do so because of two reasons. First, the whole notion of defining a native speaker and native speaker competence is fraught with difficulty and it is nor reasonable that it serves as the basis for research into bilingual English language use. Second, an approach to SLA research that is based on the notion that all learners of English need or desire 'native speaker competence' will contribute little to a better understanding of their various language needs.

Clearly, teaching English as an international language requires that researchers and educators thoroughly examine individual learners specific uses of English within their particular speech community as a basis for determining learning goals and even more important is that it requires that they set aside the fallacy whereby multilingual speakers of English, both in research and pedagogy, are constantly compared with native speaker models.

Today eighty percent of English language teaching professionals worldwide are bilingual users of English (CANAGARAJAH, 1999). Despite of this, the fallacy of comparing non-native English - speaking teaching professionals to native speaker is widespread. The native speaker fallacy is based on the Chomskyan notion that the native speaker is the ideal informant in grammatical judgments and is, therefore, the ultimate authority on language use. One of the most unfortunate repercussions of the concept of native speaker fallacy in reference to language teaching is its positioning of bilingual users of English in the ELT market. In many English teaching institutes around the world, the native-speakers of English are giving preference in hiring. Such perspective places the bilingual teacher of English at a severe disadvantage in the job market.This narrow view of professionalism can have damaging effects on bilingual English teachers in the Outer and expanding Circle. Those professional feel compelled to spend undue time repairing their pronunciation or performing other cosmetic changes to sound native. Their predominant concern is in effect "How can I lose my accent?" rather 
than "How can I be a successful teacher?" In reference to pronunciation, once again the native speaker model needs to be carefully examined. As Jenkins (1998) points out, a more realistic approach to pronunciation may be to treat the native speaker model not as a goal for pronunciation but rather as a point of reference to prevent nonnative varieties from moving too far apart from each other. Some researches is social psychology have demonstrated clearly the links between accent, pronunciation and personal and group identity, however popular attitudes to pronunciation are, as the social-psychological literature tells us, firmly entrenched and very slow to alter.

But pronunciation is not the only factor that can lead bilingual English teacher to experience a good deal of insecurity on his or her own abilities. Tang (1997), for instance, reports, on a survey she conducted of a teacher training course in Hong Kong where she found out, that a very high percentage of the teachers believed that native English speaking teachers were superior to non-native English-speaking teachers in speaking (100 per cent), pronunciation( 92 per cent), listening (87 per cent), vocabulary( 79 per cent) and reading (72 per cent). The insecurity of bilingual English teachers is perhaps even more acutely felt when these teachers are working in the Inner Circle countries. Not only the teachers feel insecure in terms of pronunciation and linguistic knowledge, but they also feel insecure in terms of their cultural knowledge regarding to that particularly English-speaking country. The fact that in their eyes they were less competent teachers of English because they did not have specific knowledge about cultural aspects of the country suggests that they view the acquisition of English as necessary linked to acquiring the culture and identity of an Inner Circle country. It is encouraging, however, that more and more educators are challenge the native speaking fallacy and pointing out the many strengths of competent teachers of English who share a first language with their students and have gone through the process of learning English as an additional language.

Seidhlhofer (1999) has contributed a lot to the process by describing the many strengths of bilingual teachers of English. Among them we can point out the sense of "double agents", in a sense that they know the language and culture of their students as well as the target language, they are aware of how English fits into students' linguistic repertoire and they are familiar with different varieties and where these varieties are appropriately used. Another advantage of bilingual teachers is that, since they have gone through the process of acquiring English as a second language themselves, they often have developed awareness of the structure of the language; in addition, they can anticipate the problems their students may have in acquiring it, for that reason the ability of local teachers to design appropriate pedagogy should not be underestimated since they are in the best position to be able to asses the effectiveness of methods and materials for their local context.

Ultimately, being able to do all, this provides bilingual teachers with a sense of what their students need to know. But perhaps the greatest strengths of bilingual English teachers is that, they provide their students with a model of a good language learner that is relevant to their language own social and cultural experience, a model that no language teacher from another culture can ever provide.

\subsection{Language standards}

The issue of standards exists in all languages. Whereas no comparable body exists to regulate the use of English, the desire to uphold standards is clearly present. With the spread of English and the resulting variation in the language, some people believe that the need to uphold common standards has increased in importance. It is puzzling that whereas differences in the use of English between Inner Circle countries are generally accepted with no one suggesting that this will lead to incomprehensibility, language variation outside Inner Circle countries is often seen as a treat.

Central to this debate, of course, is what is meant by standards or norms. Stevens (1983) defines Standard English as "A particular dialect of English, being the only non-localized dialect, of global currency without significant variation, universally accepted as the appropriate educational target in teaching English; which may be spoken with an unrestricted choice of accent”. Others associate Standard English particularly with the written form of language.

But, if different norms develop in different varieties of EIL, will this ultimately lead to a lack of mutual intelligibility among them? To answer this question we need to consider what is meant by intelligibility. This is a complex matter, involving what some linguistic refer to as 'intelligibility' (recognizing an expression), comprehensibility (knowing the meaning of a expression), and interpretability (knowing what the expression signifies in a particular sociocultural context). For example, if a listener recognizes a world is an English world rather than a Spanish one, English is then intelligible to him, if he, in addition, knows the meaning of the word, it is comprehensible to him and if he understands this word in a sentence, then he is able to interpret the language.

Despite of the fact the term intelligibility is used to cover all three types of meaning, it is worth nothing that, in many ways, it is what is referred to as interpretability that causes the greatest problems in the use of EIL for cross- cultural communication since interpretability entails questions of culture and context. It is important 
to note that when English is used cross culturally, it is possible that the speakers will work together to achieve interpretability.

\section{2- The English Language.}

One question whish arises in any discussion of global English is whether single world standard English will develop, forming supranational variety which must be learned by global citizens of the $21^{\text {st }}$ century. There are at least two dimensions to the question: the first is whether English will fragment into many mutually unintelligible local forms; the second is whether the current 'national' standards of English (particularly US and Britain) will continue to compete as models of correctness for world usage, or whether some new world standard will arise which supersedes national model for the purpose of international communication and teaching.

The widespread use of English as a language of wider communication will continue to exert pressure towards global uniformity. But as English shifts from foreign language to second-language status for an increasing number of people, we can also expect to see English to develop a larger number of local varieties. These contradictory tensions arise because English has two main functions in the world: it provides a vehicular language for international communication and its form the basis for constructing cultural identities. The former function requires mutual intelligibility and common standards. The latter encourages the development of local forms and hybrid varieties. There is no need to fear, however, that trends towards fragmentation will necessary threaten the role of English as a "língua franca". There have been since the first records of the language, major differences between varieties of English.

The mechanism which have helped to maintain standard usage in the past may not, however, continue to serve this function in the future. Two major technologies have helped develop national, standard-language forms. The first was printing, the invention of which provided a "fixity" in communication by means of printed books. But with increasing use of electronic communication much of the social and cultural effect of the stability of print has already been lost. The second technology has been provided by broadcasting, which in many ways became more important than to print in the socially mobile communities of the $20^{\text {th }}$ century. But trends in global media suggest that broadcasting will not necessarily play an important role in establishing and maintaining a global standard.

Meanwhile, new forms of computer mediated communication are closing the gap between spoken and written English that had been constructed laboriously over centuries. And cultural trends encourage the use of informal and more conversational language, a greater tolerance of diversity and individual style, and a lessening deference to authority. These trends, taken together, suggest that a weakening of the institutions and practices which maintained national standard languages is taking place: that the native-speaking countries are experiencing a 'destandardization' of English.

The English Language Teaching industry, however, may play an important role in maintaining an international standard as Stevens (1992) suggested:

"There exists an unspoken mechanism, operated through the global industry of ELT teaching, which has the effect of preserving the unity of English in spite of its great diversity. For throughout the world, two components of English are taught and learned without variation: these are its grammar and its core vocabulary."

However, second-language countries are likely to develop their own curricula, material and teacher resources that they try to export to neighboring countries. In some parts of the world, this may help bring new, non-native models of English -supported by dictionaries and pedagogic materials- into competition with the older standard varieties.

\section{3- Teaching English as an International Language}

The teaching of EIL today takes place in a wide variety of contexts: in Outer and Expanding Circle of countries, in private and public institutions, with young children and adults, with monolingual and bilingual teachers. Although there is great diversity among these contexts, all of them share the goal of developing proficiency in the learning of an international language.

The literature on English as an International Language (EIL) methodology is filled with characterizations of the culture of learning of various countries. The discussions towards this subject provide generalizations regarding to the typical role of teachers and students as well as the nature of learning and reflect a received view of culture in which a particular culture is seen as a homogenous entity related to a specific geographical region.

Such a view of homogeneity raises several problems. First, they mask the diversity that exists within any culture, second, in many instances characteristics that are attributed to a particular culture of learning are not supported by studies based on extensive classroom observation. Third, and the most important in the teaching of an international language is that such characterizations of cultures of learning often contrasts a particular culture of learning with western cultures, resulting in ideas of otherness and foreignness. Kubota (1996 p. 16) argues 
that labels that symbolize "a cultural dichotomy serve to create and perpetuate, rather than reflect cultural differences". The comparison of various nonwestern cultures with western ones suggests that in some ways the latter are the standard and hence should provide the model for the teaching of English. However, in the teaching of an international language, bilingual users should be allowed to take ownership not only of the language but also of the methods used to teach it. Although no one would deny that cultural differences do exist, Kubota (1992 p.27) believes it is essential that describing cultural differences is not viewed as an end itself; rather, educators must seek to understand how 'difference is produced, legitimated, and eliminated within unequal relations of power'.

The history of English as an International language (EIL) is usually described as if one method followed another. In Brown's description (1994), all of these methods were superseded by the present -day emphasis on Communicative Language Approach (CLT). Such a view of teaching methodology, especially in relation to the teaching of EIL, has several problems. First, such historical accounts of language teaching, to the extent that, they are accurate, primarily reflect the history of language teaching in Inner Circle countries. Second. If one looks at EIL in a global context, it is clear that many methods now described in methodology texts are no longer being used, for example, grammar translation and audiolingualism are still used in countries outside the Inner Circle. Finally, in many cases, it would be difficult to characterize a particular classroom as using only one method or approach.

These problems lead to a question that seems very important to be answered, is CLT the most productive approach for teaching English? Tollefson (1991) suggest that the spread of English is linked to what he terms the 'modernization theory'. According to this theory, 'Western societies provide the effective model for "underdeveloped" societies. When applied to EIL teaching, in modernization theory, western "experts" are viewed as repositories of knowledge and skills who pass them on to elites who will run "modernized" institutions'. The fact is that CLT has spread both because of the promotion of the approach by western specialist and because educators in these countries have advocated its adoption. In a variety of countries, educational leaders have chosen to attempt to implement the use of CLT in the belief that this is the most modern and productive way to teach English.

A final factor that has clearly contributed to the spread of CLT is the textbooks. Many current ELT textbooks, published in the Inner Circle countries, encourage activities which support the CLT in that a premium is placed on oral activities in which students interact with classmates. These discussions demonstrate that just as the Inner Circle is often looked for target models of language use, it is also frequently looked to for methodology models. Whereas this dependency of Outer and Expanding Circle countries may in part be due to a type of 'pedagogical imperialism' on the part of Inner Circle educators, there is no question that, just as with the spread of English, an equally important factor in the spread of CLT has been its conscious selection on the part of local educators.

Today the use of English and the teaching of EIL is embedded in a variety of local contexts. Every EIL classroom is influenced by various contextual factors. These include the political and social context, the educational institution itself, the teachers' and students' background. Consequently, each classroom is unique in the particular dynamic that exist among the participants in a lesson. Because of this, as Prabu (1990) points out, "there is no one best method, and no one method that is best in a particular context' and he also suggest that, "there is a factor more basic than the choice between methods, namely teachers'.

For Prabhu (1990), there is a sense of plausibility that is influenced by teachers' own experience in the past as learners, by their experience teaching, and by their exposure to one or more teaching methods. A method then would be a highly developed and highly articulated sense of plausibility. EIL educators are involved in teaching an international language that no longer belongs to any one nation or culture, then it is reasonable that the way in which this language is taught should not be linked to a particular culturally influenced methodology; rather, the language should be taught in a consistent matter with local cultural expectations. In others words, an appropriate EIL methodology presupposes sensitivity to the local cultural context in which local educators, on the basis of their sense of plausibility, determine what happens in the classroom.

Therefore the view of an appropriate pedagogy is keeping with the local political motto, in languageteaching terms, it should be adopted a global thinking considering a local teaching. Since teaching of EIL takes place in a wide diversity of contexts it is naïve to assume that one method is best for all. Clearly, in the teaching of EIL, local educators should have control over how English is taught, implementing a methodology that is appropriate and relevant to the local context rather than looking to Inner Circle Countries for models. However, this is not without its problems.

Those that defend the development of a locally appropriate pedagogy argue that its design must be in the hands of local educators. Although what is not clear, is exactly what 'local educators' mean. One could argue that it is the individual classroom teacher who needs to define an appropriate pedagogy for his or her classes. In many cases, this is reasonable. The individual classroom teacher, after all, is the one who knows the needs of the students, and must take the moment-by-moment decisions of classroom content and interaction in 
order to meet these purposes. From another perspective, however, the classroom teacher needs support from a larger educational context to develop an appropriate pedagogy. At the end, it's quite important to recognize that local educators are composed of various interest groups, often having different and competing perspective and agendas.

\subsection{1- Goals of teaching English as an international Language (EIL).}

The fact that the spread of English has, as it is natural, brought with it language changes and variation suggests that one goal of EIL teaching is to ensure intelligibility among the speakers of English. In the teaching of, it is important to distinguish linguistic differences that create problems of intelligibility from those that may engender negative attitudes. In this area, educators want to strive to minimize the differences. Hence, particular pronunciation and grammatical patterns and, in some cases, lexical innovations that cause problems of intelligibility need to be addressed. Language differences that do not cause intelligibility problems, but reflect negative attitudes, also need to be addressed but in a different way. In this case, the lack of intelligibility results not from features of the language itself but from the social attitudes that surround particular linguistic features. As speakers take ownership of English, they will likely change the language. Those changes that do not impede intelligibility should be recognized as one of the natural consequences of the use of English as an international language.

A second goal should be to help learners develop strategies to achieve comity-friendly relations- when English is used with speakers from other cultures. When speakers come to the language for cross-cultural purposes, they may need to learn some aspects of pragmatic competences. Traditionally, the teaching of pragmatics for the use of English in such circumstances has assumed a 'native-speaker' target, but since native speaker models are inappropriate in teaching an international language, the goal of teaching pragmatic in EIL should not be to achieve native-like competence but rather to encourage the acquisition of interaction strategies that will promote comity.

A final goal in the teaching of EIL should be to develop textual competence. One of the primary reasons for learning English today is to access and contribute to the large amount of information that is available nowadays. This availability of information suggests that the primary goal of many learners will be to develop reading and writing skills. When teaching reading in EIL, teachers should encourage a view of it, as an interactive process in which readers must take an active role in making sense of texts, particularly, when the texts exemplify different rhetorical patterns from their own.

Finally, EIL should be taught respecting the local culture and that culture should not be based on stereotypes. Assertions made about traditional roles of teachers and students should be avoided because they are often references of European cultures. Although, it is important to recognize that what happens in a specific classroom is influenced by political, social and cultural factors that exist in the larger community; each classroom is unique in the way the learners and teacher interact with one another in the learning of English.

The concept of thinking globally but acting locally is deeply relevant to the teaching of EIL. The evidences show that the use of EIL will continue to grow and English is going to be a language that belongs to no one and at the same time to everyone. Given this shift in ownership, it's about time for decisions regarding to teaching goal and approaches to be given to local educators because, at the end, they are in the best position to understand what their students need to know and how they will acquire it.

Our chapter has started retaking some of the questions previously discussed, then we put into debate the impacts of English in a globalized and post-modern world. Having done that our next task was to study the possibility of creating a standard language emphasizing the English language.To finish that chapter, we analyzed the teaching of English as a "Lingua Franca" and the reasons for its learning, without considering, for a matter of time, the relevance of the impacts of the cultural imperialism.

\section{Conclusion}

For concluding this research, we will restrict ourselves to demonstrate the following points:

In the first chapter, we were to discuss that by 2050 , there will be around 433 million of English native speakers and 668 millions of non-native speakers, and that the decline of the native speaker does not reflect the decline in the importance of the English language. This because the future of the language would be more related to the growing number of people who uses it as a second or a foreign language than the natives speakers themselves.

The language shift towards English all over the world will reflect the increasing of bilinguism and multilinguism rather than an abandonment of other languages, for that reason people may not be afraid of losing its cultural identity. Nowadays, there are many ways to divide the English speaking community, but authors can't get to a conclusion which is more appropriate to face the changes that are going on within these communities. According to the second chapter, there is no reason to believe that any other language will appear in the next 50 years to replace English as a "Lingua Franca" but some languages as Spanish, Mandarin may have great regional influence. In comparison with today, in the future, there will be more languages in the top 
layer but the biggest difference may be the loss of several world's language, hence there may be a smaller group of languages in the apex layer. Migration has been one of the main reason for the arose of English, even with the changing in patterns of the migration, there is still a great number of people moving for different reasons all over the world. Urbanization is another important fact in the spread of English, in the world's cities the advance of English will be first felt and new patterns will arise amongst second-language speaker.

In the third chapter, we could realize that the focus of SLA research is that the goal of English language is to achieve native-like competence but this needs to change in order to fit the different necessities that learners have nowadays. Today, $80 \%$ of English teachers are bilingual users of English and those teachers feel very much insecure with their pronunciation, linguistic and cultural knowledge. However, more teachers are starting to challenge the native speaker fallacy and are pointing out the advantages of sharing the same first language with their students, and most of all have gone through the process of learning the language themselves, what provides students a model of a good language learner that is relevant to the students' learning process.

Another important point is whether there will be a Standard English or not. Some authors claim that, despite of all varieties that can emerge from this situation, it would emerge an educated variety that would be intelligible across the others. The teaching of EIL today takes place in a variety of contexts and EIL educators are involved in teaching a language that no longer belongs to any nation, consequently the methodology they use shouldn't be influenced by any particular country, because the best method is the one that can fit the specific needs of the community.

Above all, teachers need to be aware that students are going to communicate with people of different cultures and sometimes, using different varieties of English and this will not serve as a barrier for communication, but as an enrichment for the people involved and also for the language itself. Having this in mind, we will have to reexamine our classes and our practices. Are we charging our students with what will really cause a breakdown in communication? Are we preparing them for the differences and helping them to deal with it? All this will influence, from now on, the teaching of English language.

\section{References}

[1] Graddol, D. The future of English? London: The British Council, 1997

[2] MacArthur, T. The English Language Cambridge: Cambridge University Press, 1998

[3] Crystal, D. English as a global language Cambridge: Cambridge university Press, 1997

[4] Mazzuri, A. the world banck the language question and the future of Africa Education, race and Class, 38(3), 35-48, 1997

[5] Baumgardner, R. J. South Asia English, structure, use and users Chicago: University of Illinois Press, 1996

[6] Kachru, B.B. Standards, codification and sociolinguistic reality realism: the English language in the other circle. In R. Quirk and H. G. Widdowson Eds) English in the World: teaching and learning the language and literature (Cambridge: Cambridge University Press, 1985 ) 11-30

[7] Medgyes, P. The non native teacher London: MacMillian, 1994

[8] Swales, J. English as a tyrannoussaurus rex, World Englishes, 16(3), 373-382, 1997

[9] Eco, U.The search for the perfect language Oxford: Blackwell, 1995

[10] Bailey, R.W. Images of English: a cultural history of the language Cambridge: Cambridge University Press, 1992

[11] UNDP. Human development report oxford: Oxford University Press, 1996

[12] Appadurai, A. Disjuncture and difference in the global cultural economy. Theory culture and society, 7, London, Sage, 1990, 295310

[13] Canagarajah, A.S. Resisting linguistic imperialism in English teaching. Oxford: Oxford University Press, 1999

[14] Jenkins, J. Which pronunciation norms and models for English as an International Language? ELT Journal, 50 (2), 1998, 119-126

[15] Tang, C. On the power and status of nonnative ESL teachers. Tesol Quaterly, 31(3) 1997, 577-583

[16] Seidlhofer, B Double standards: teacher education in the expanding circles, World Englishes, $18(2), 1999233$ - 245

[17] Stevens, P. English as an international language: direction in the 1990s. In: B.B. Kchru (Ed.) The other tongue: English across culture. $2^{\text {nd }}$ ed. Urbana: University of Illinois Press, 1992

[18] Stevens, P. What is standard English? In: L. Smith (Ed) readings in English as an international language Oxford: Perdagon Press, 1983, 87-93

[19] Tollefson, J.W. Planning language, planning inequality London: Longman, 1991

[20] Prabbu, N.S. There is no best method - why? Tesol Quaterly, 24(2), 1990, 161-176

[21] Sridhar, S.N.; Sriddar, K.K. indigenizd englishes as second languages: towards a functional theory of second language acquisition in multicultural contexts. In: R.K. Agnihotri and A.L. Khanna (Eds) second Language Acquisition: socio-cultural and linguistic aspects of English in India London: Sage Publications, 1994, 41 - 63

[22] Brown, H. D. Teaching by principles: an interactive approach to language pedagogy. Englishwood cliffs (NJ) Prentice Hall Regents, 1994 